\title{
Pengaruh Faktor Psikologis Terhadap Pengambilan Keputusan Wisatawan dalam Mengunjungi Taman Bunga Nusantara Kabupaten Cianjur
}

\author{
Eka Nuraisah Rosiana*1, Piek Haeryah Sadkar², Bem Hainim³ \\ Sekolah Tinggi Pariwisata Bandung, Indonesia ${ }^{1,2,3}$ \\ Email: ekanuraisah@stp-bandung.ac.id
}

\begin{abstract}
Psychological factors are factors inherent in the individual, which will affect how the various kinds of stimuli given by marketers, will affect consumer recognition of the needs, information seeking, and a variety of alternatives before deciding to make a visit or not. This research, entitled "The Influence of Psychological Factors on Tourist Decision to Visit Taman Bunga Nusantara Cianjur Regency" conducted in order to determine the psychological factors of tourist and the decision-making of tourist in visiting Taman Bunga Nusantara Cianjur Regency, as well as to analyze the influence of psychological factors towards tourist decision making to visit Taman Bunga Nusantara Cianjur Regency. The used method is accidental sampling. Respondents in this research were the visitors of Taman Bunga Nusantara as the location of the research, a total of 120 respondents. Based on the analysis, the firmest aspect of psychological factors is personality. As well as tourist decision in visiting Taman Bunga Nusantara was in the low category. Simultaneously, psychological factors significantly influence tourist decision in visiting Taman Bunga Nusantara Cianjur Regency. Based on the research results, the manager of the Taman Bunga Nusantara in order to create a marketing strategy that can affect consumers by providing a strong stimulus to be remembered very well by travelers.
\end{abstract}

Keywords: Tourism Development; Tourism Policies; National and International Level; Tourism Product and Market.

\begin{abstract}
Abstrak
Faktor psikologis adalah faktor yang melekat pada individu, yang akan mempengaruhi bagaimana berbagai macam rangsangan yang diberikan oleh pemasar, akan mempengaruhi pengenalan konsumen akan kebutuhan, pencarian informasi, dan berbagai alternatif sebelum memutuskan untuk melakukan kunjungan atau tidak. Penelitian ini yang berjudul "Pengaruh Faktor Psikologis Terhadap Keputusan Wisatawan Mengunjungi Taman Bunga Nusantara Kabupaten Cianjur" dilakukan untuk mengetahui faktor psikologis wisatawan dan pengambilan keputusan wisatawan dalam berkunjung ke Taman Bunga Nusantara Kabupaten Cianjur, serta untuk menganalisis pengaruh faktor psikologis terhadap pengambilan keputusan wisatawan untuk mengunjungi Taman Bunga Nusantara Kabupaten Cianjur. Metode yang digunakan adalah accidental sampling. Responden dalam penelitian ini adalah pengunjung Taman Bunga Nusantara sebagai lokasi penelitian, sebanyak 120 responden. Berdasarkan analisis, aspek yang paling kuat dari faktor psikologis adalah kepribadian. Serta keputusan wisatawan dalam mengunjungi Taman Bunga Nusantara termasuk dalam kategori rendah. Secara bersamaan, faktor psikologis secara signifikan mempengaruhi keputusan wisatawan dalam mengunjungi Taman Bunga Nusantara Kabupaten Cianjur. Berdasarkan hasil penelitian, pengelola Taman Bunga Nusantara dalam rangka menciptakan strategi pemasaran yang dapat mempengaruhi konsumen dengan memberikan stimulus yang kuat agar diingat dengan baik oleh para wisatawan.
\end{abstract}

Kata Kunci: Pengembangan Pariwisata; Kebijakan Pariwisata; Tingkat Nasional dan Internasional; Produk dan Pasar Pariwisata.. 


\section{A. PENDAHULUAN}

Pada dasarnya keputusan untuk melakukan perjalanan wisata sama dengan keputusan pembelian, yaitu mengeluarkan uang untuk mendapatkan kepuasan. Menurut Mathicson dan Wall, ada 5 langkah dalam proses pengambilan keputusan seorang wisatawan (1982:95) 'felt need/travel desire, information collection and evaluation image, travel decision (choice between alternative), travel preparation and travel experiences, travel satisfaction outcome and evaluation ". Dart pernyataan tersebut dapat dilihat bahwa proses pengambilan keputusan ini terdiri kcbutuhan untuk melakukan perjalanan, pencarian dan penilaian informasi, keputusan melakukan perjalanan wisata, persiapan perjalanan dan pengalaman wisata, serta evaluasi kepuasan peijalanan wisata.

Keputusan berkunjung wisatawan ke sebuah destinasi wisata ini bisa disebabkan oleh beberapa faktor yaitu lingkungan, pribadi, dan psikologis (Sutisna, 2006:55). Faktor lingkungan ini terdiri dari beberapa variabel yaitu budaya, sosial, dan keluarga. Sedangkan faktor pribadi (Kotler \& Keller, 2009:172), meliputi aspek-aspek seperti usia, tahap siklus hidup, pekerjaan, keadaan ekonomi, kepribadian, dan gaya hidup. Faktor lain yang mempengaruhi keputusan wisatawan untuk mengunjungi sebuah daya tarik destinasi adalah faktor psikologis (Kotler, 2009:176), yang dapat dibedakan menjadi motivasi, persepsi, pembelajaran, keyakinan dan sikap. Sementara faktor-faktor psikologis utama yang mempenearuhi pilihan pembelian yang dikemukakan oleh Schiffman \& Kanuk (2007:7) terdiri dari motivasi, persepsi, pembelajaran/pengetahuan, kepribadian, dan sikap.

Sedangkan menurut Best, Hawkins \& Cooney, proses pengambilan keputusan ini dipengaruhi oleh external influences dan internal influences (2001:3). External influences ini terdiri dari 1.culture, 2.subculture, 3 demographics, 4.social status, 5. refenrence groups, 6. family, dan 7.marketing strategy. Sedangkan internal influences ini terdiri dari I perception, 2.learning, 3.memory, 4.motives, 5.personality, 6.emotions, dan 7.attitudes. Dari pernyataan tersebut dapat dilihat bahwa aspek-aspek yang terdapat pada internal influences yang dikemukakan oleh Best, Hawkins \& Cooney memiliki kesamaan dengan aspck-aspekyang ada pada faktor psikologis yang dikemukakan oleh beberapa ahli lainnya.

Pada kesempatan ini penulis menitikberatkan permasalahan kepada internal influences atau faktor psikologis wisatawan. Karena penulis menduga bahwa factor-faktor psikologis dari wisatawan adalah faktor yang paling dominan dalam menentukan keputusan mercka untuk mengunjungi Taman Bunga Nusantara atau tidak. Karena faktor psikologis adalah faktor yang paling melekat pada diri individu, yang akan mempengaruhi bagaimana berbagai macam rangsangan yang diberikan oleh pengelola Taman Bunga Nusanatra, akan mempengaruhi pengenalan konsumen terhadap kebutuhan, pencarian informasi, dan berbagai alternatif sebelum memutuskan untuk melakukan kunjungan atau tidak.

Hal tersebut sejalan dengan yang diungkapkan oleh Kotler \& Keller (2009:176) yaitu faktorfaktor psikologis diartikan sebagai nilai inti (core values), system kepercayaan yang mendasari sikap dan perilaku. Nilai inti lebih dalam dari pada perilaku atau sikap dan menentukan pilihan dan keinginan seseorang pada tingkat dasar dalam jangka panjang.

Menurut Kotler \& Keller (2009:176-177) titik awal untuk memahami perilaku konsumen adalah adanya rangsangan pemasaran dari luar seperti ekonomi, teknologi, politik dan budaya. Satu perangkat psikologi berkombinasi dengan karakteristik konsumen tertentu untuk menghasilkan proses keputusan dan keputusan pembelian. Tugas pemasar adalah memahami apa yang terjadi dalam kesadaran konsumen antara datangnya rangsangan pemasaran luar dengan keputusan pembelian akhir. Empat proses psikologis (motivasi, persepsi, ingatan, dan pembelajaran) secara fundamental, mempengaruhi tanggapan konsumen terhadap rangsangan pcmasaran.

Berdasarkan hasil wawancara awal yang dilakukan dengan bagian Humas Taman Bunga Nusantara, diketahui bahwa tingkat kunjungan ke Taman Bunga Nusantara selama 10 tahun terakhir 
mengalami keadaan yang sangat fluktuatif. Dalam observasi awal penulis melakukan wawancara singkat dengan masyarakat umum. Kepada masyarakat umum penulis meminta tanggapan mengenai beberapa faktor psikologis yang akan mendorong keputusan mereka untuk mengunjungi Taman Bunga Nusantara.

Dari aspek perception, diketahui bahwa masyarakat memiliki persepsi bahwa Taman Bunga Nusantara adalah tempat untuk berekreasi. Padahal apabila dilihat dari tujuan utama dari dibangunnya Taman Bunga Nusantara adalah sebagai tempat rekreasi dan tempat penelitian serta percobaan berbagai jenis bunga dan tanaman dari berbagai Negara. Sedangkan untuk aspek motives diketahui bahwa masyarakat umum merasa motivasi wisata mereka tidak akan terpenuhi secara maksimal di Taman Bunga Nusantara. Sementara untuk aspek learning dan memory diketahui bahwa masyarakat umum merasa bahwa media pemasaran yang ada tidak dapat memberikan informasi yang tepat yang bisa mereka ingat dengan baik.

Sejalan dengan pemikiran tersebut di atas, pihak pengelola Taman Bunga Nusantara perlu memahami apa yang terjadi dalam kesadaran setiap konsumen pada saat adanya berbagai macam rangsangan pemasaran luar seperti situasi ekonomi, politik, teknologi, dan budaya. Hal ini ditujukan agar pihak pengelola dapat memutuskan strategi pemasaran yang paling sesuai untuk digunakan. Sehingga faktor-faktor psikologis yang melekat pada diri konsumen dapat menghasilkan tanggapan yang positif terhadap Taman Bunga Nusantara.

\section{B. METODE PENELITIAN}

Jenis penelitian yang digunakan bersifat dcskriptif analitis yaitu penelitian yang menggambarkan sifat suatu keadaan yang sementara berjalan pada saat penelitian dilakukan, dan memeriksa sebab-sebab dari suatu Qejala tertentu. Penelitian dilakukan dengan cara mengumpulkan data dalam rangka menguji hipotesis atau menjawab pertanyaan yang menyangkut keadaan pada waktu yang sedang berjalan dari suatu pokok penclitian. Penelitian ini dilakukan dengan menggunakan pendekatan kuantitatif untuk membuktikan seberapa besar pengaruh antara faktorfaktor psikologis dengan keputusan berkunjung wisatawan ke Taman Bunga Nusantara.

Untuk memperoleh data yang dibutuhkan, penulis menggunakan alat pengumpul data sebagai berikut:

\section{Wawancara}

Wawancara menurut Sugiyono (2005:157) adalah : "...teknik pengumpulan data apabila peneliti ingin melakukan studi pendahuluan utnuk menemukan permasalahan yang hams diteliti, dan juga apabila peneliti ingin mengetahui hal-hal dari responden yang lebih mendalam ...". Penulis melakukan pembicaraan atau tanya jawab secara langsung dengan bagian Humas Taman Bunga Nusantara sesuai dengan masalah yang dibahas sehingga data yang diperoleh dapat dipertanggungjawabkan kebenarannya dan relevan dengan permasalahan yang diangkat.

\section{Kuesioner/Angket}

Teknik pengumpulan data yang dilakukan dengan cara member seperangkat pertanyaaan atau pernyataan tertulis kepada responden untuk dijawabnya. Dengan menggunakan angket tertutup sebagai teknik pengumpulan data akan mempermudah peneliti dalam melakukan analisis data dari seluruh angket sehingga dapat menghemat waktu. Pertanyaan dalam angket dibuat dalam bentuk pertanyaan, dan setiap alternatif diberi nilai dengan membeli skala Likert dengan pemberian skor sebagai berikut:

a. Sangat setuju 

b. Setuju (3)
c. Tidak setuju
d. Sangat tidak setuju

\section{(1)}

\section{Uji Validitas}

Uji validitas digunakan untuk mengukur sah atau tidaknya satu kuesioner (Ghozali, 2001:177). Satu kuesioner dinyatakan valid jika pertanyaan pada pertanyaankuesioner mampu mengungkapkan sesuatu yang akan diukur oleh kuesioner tersebut. Tingkat validitas dapat diukur dengan cara membandingkan nilai rhituugpada tabel Correlations pada total nilai Pearson Correlation untuk tiap indikator variabel dengan nilai rtabeldengan ketentuan untuk degree offi•eedom (df) $=n-k$ dimana $n$ adalah jumlah sampel yang digunakan dan $\mathrm{k}$ adalah jumlah variable independennya. Dengan jumlah sampel (n) adalah dan tingkat signifikansi 0,05 maka rtabel pada penelitian ini adalah: $\mathrm{r}(0,05 ; 70-3)$ $=67$

Bila : $\quad$ rhitung $>$ rtabel, berarti pernyataan tersebut dinyatakan valid. rhitung<rtabel,abet, berarti pernyataan tersebut dinyatakan tidak valid.

\section{Uji Reliabilitas}

Uji reliabilitas digunakan untuk mengukur kuesioner yang merupakan indikator dari variabel. Kuesioner dikatakan reliabel atau handal jika masing-masing pertanyaan dijawab responden secara konsisten atau stabil dari waktu ke waktu. Suatu kuesioner dikatakan handal jika nilai Cronbach Alpha lebih besar dari 0,600 (Ghozali, 2001:183).

\section{Analisis Jalur}

Sebagai langkah terakhir dari analisis data adalah pengujian hipotesis. Teknik analisis data yang digunakan dalam penelitian ini adalah analisis jalur atau path analysis. Analisis jalur digunakan untuk menganalisis pola hubungan kausal antar variabel dengan tujuan untuk mengetahui pengaruh langsung dan tidak langsung, secara serempak atau mandiri beberapa variabel penyebab $(X)$ yaitu perception (Xi), learning (X2), memory (X3), motives (X4), personality (Xs), emotions (Xs), attitudes (X7) terhadap variabel variabel akibat (Y) yaitu keputuasn berkunjung.

Adapun teknik analisis jalur dijalankan dengan langkah sebagai berikut:

a. Menggambar dengan jelas diagram jalur yang mencerminkan proposisi hipotetik yang diajukan, lengkap dengan persamaan strukturalnya.

b. Menghitung matriks korelasi antar variabel.

Untuk menghitung koefisien korelasi digunakan Pearson's Coefficient of Correlation (Product Moment Coefficient) dari Karl Pearson.Alasan penggunaan teknik koefisien korelasi dari Karl Pearson ini adalah karena variabel-variabel yang hendak dicari korelasinya memiliki skala pengukuran interval. Rumus Pearson's Coefficient of Correlation (Product Moment Coefficient):

Menghitung matriks korelasi variabel exogenous.

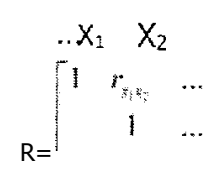

(1) Menghitung matriks invers korelasi variabel exogenous.

$$
\begin{array}{r}
\mathrm{x} 1 \times 2 \ldots \mathrm{Xk} \\
{ }_{C} C_{,} C^{\prime} ., \ldots \mathrm{C} . .
\end{array}
$$




$$
\mathrm{Rif}^{\prime}=\left|\begin{array}{cccc}
\cdots & \ldots & & * \\
& C_{32} & \ldots & C_{3 \alpha} \\
& & \ldots & \ldots
\end{array}\right|
$$

(5) Menghitung semua koefisien jalur $\mathrm{p}, 2, \ldots \mathrm{k}$; melalui rumus:

$$
\text { Ca } c i 2 \text { Cix }
$$

(6) Menghitung besamya pengaruh langsung, pengaruh tidak langsung serta pengaruh total variabel exogenous terhadap variabel endogenous secara parsial, dengan rumus:

- Besarnya pengaruh langsung variabel exogenous terhadap variabel endogenous $=\mathrm{p} \times \mathrm{p}$

- Besarnya pengaruh tidak langsung variabel exogenous terhadap variabel endogenous $=\mathrm{p} \times \mathrm{r} \times \mathrm{px} .-=$.

- Besarnya pengaruh total variabel exogenous terhadap variabel endogenous adalah penjumlahan besarnya pengaruh langsung dengan besarnya pengaruh tidak langsung

$$
\operatorname{xpxux},]+[p x . . ;, x \quad r, T=x
$$

(7) Menghitung, yaitu koefisien determinasi total $X_{1}, X k$ terhadap $X$ atau besarnya pengaruh variabel exogenous secara bersama-sama (gabungan) terhadap variabel endogenous dengan menggunakan rumus:

$$
R=p \cdot Z_{y}, Z, \quad P X^{\sim} . \quad \ldots
$$

(8) Menghitung besarnya variabel residu, yaitu variabel yang mempengaruhi variabel endogenous di luar variabel exogenous dengan rumus:

$$
t-=v 1-R \times x,(x, x, \ldots, \ldots, 1
$$

(9) Menguji kebermaknaan (test of significance) setiap koefisien jalur yang telah dihitung, dengan statistik uji yang digunakan adalah (Al Rasyid, 2005):

$1\left(1-R^{\prime} r_{u}\left(x x_{z}\right.\right.$

$n-k-1$

dengan:

$\mathrm{i}=1,2, \ldots \mathrm{k}$

k= Banyaknya variabel exogenous dalam sub struktur yang sedang diuji

$\mathrm{t}=$ Menaikuti tabel distribusi t-student, dengan derajat bebas (degrees of freedom) $\mathrm{n} \sim-\mathrm{k}-1$ 
Kriteria pengujian: Ditolak Ho jika nilai hitung t lebih besar dari nilai tabel t student. (to> ttabel(n-k-1)).

(10) Menguji kebermaknaan (test of significance) koefisien jalur secara keseluruhan yang telah dihitung, dengan statistik uji yang digunakan adalah (Nirwana Sitepu, 1994):

$$
\begin{aligned}
& F-(n-k-1)\left(R^{\circ} \times, \mathrm{Ixxxi}\right) \\
& \mathrm{k}(1-\mathrm{R} r
\end{aligned}
$$

dengan:

$\mathrm{i}=1,2, \ldots \mathrm{k}$

$\mathrm{k}$ = Banyaknya variabel exogenous dalain sub struktur yang sedangdiuji

$\mathrm{t}=$ Mengikuti tabel distribusi $\mathrm{F}$ - Snedecor, dengan derajat bebas (degrees of freedom) $\mathrm{k}$ dan $\mathrm{n}-\mathrm{k}-1$

Kriteria pengujian: Ditolak Ho jika nilai hitung F lebih besar dari nilai table F.

$\left(\mathrm{FO}>\mathrm{F}_{\text {tabcl }}(\mathrm{k}, \mathrm{n}-\mathrm{k}-1)\right) \bullet$

(11) Menguji perbedaan besarnya pengaruh masing-masing variabel exogenous terhadap variabel endogenous, dengan statistik uji yang digunakan adalah ( $\mathrm{Al}$ Rasyid, 2005):

$$
\begin{gathered}
1_{\left(1-\mathrm{R}^{2} \cdot \mathrm{r} ; \mathrm{ts}, \mathrm{l}\right)\left(\mathrm{C}, \pm \mathrm{C}_{11}-2 \mathrm{c}\right)} \\
n-k-1
\end{gathered}
$$

Kriteria pengujian: Ditolak Ho jika nilai hitung t lebih besar dari nilai tabe] tstudent. (to> ttabel(n-k-1))•

\section{Uji Hipotesis}

Untuk mencari antara hubungan dua variabel atau lebih dapat dilakukan dengan menghitung korelasi antar variabel yang akan dicari hubungannya. Korelasi merupakan angka yang menunjukan arah dan kuatnya hubungan antar dua variabel atau lebih.Objek penelitian yang menjadi variabel bebas atau independent variable yaitu perception (Xi), learning (X2), memory (X3), motives (X4), personality (X5), emotions (Xs), attitudes (X7), terhadap variabel dependen (Y) yaitu keputusan berkunjung. Adapun yang menjadi hipotesis utama dalam penelitian ini adalah terdapat pengaruh yang signifikan faktor-faktor psikologis terhadap keputusan berkunjung wisatawan di Taman Bunga Nusantara.

\section{Pengujian Koefisien Regresi secara Simultan (Uji F)}

Uji F digunakan untuk mengetahui seberapa besar pengaruh variable independen secara bersamasama terhadap variabel dependen. Hipotesis diuji dengan uji $\mathrm{F}$ hitnng dengan rumus:

R2-

$\mathrm{k}$ 
$\mathrm{ff}(1-\sim:-$

t )

.rl $-\sim-1 \sim$

Sugiyono (2009:235)

Ket:

$\mathrm{R}=$ Koefisien korelasi ganda

$\mathrm{k}=$ jumlah variabel independen

$\mathrm{n}=$ jumlah anggota sampel

Untuk menerima atau menolak hipotesis. $\mathrm{H0}$ diterima jika F h;tun $4<\mathrm{F}$ tabel dan menolak Ho jika F hituna $>\mathrm{F}$ tabel• Tingkat kesalahan yang digunakan sebesar $5 \%$ atau 0.05 , pada taraf signifikansi $95 \%$.

\section{Pengujian Koefisien Regresi Secara Parsial (Uji t)}

Uji t Parsial digunakan untuk mengetahui hubungan variabel X dan variabel Y. Untuk uji parsial, dilakukan uji t statistik dengan rumus:

$$
r{ }_{N} 1 n-2
$$

$t=$ (Sugiyono, 2005:214)

A) $1-$

Keterangan:

thitung = nilai $\mathrm{t}$

$r=$ Nilai koefisien korelasi

$\mathrm{n}=$ Jumlah sampel

Pengujian hipotesis secara parsial dilakukan dengan menguji nilai thinutg. Uji t bertujuan untuk menguji tingkat signifikan dari setiap variabel bebas (X1,X2dan X3) secara parsial terhadap variabel terikat (Y). Kriteria untuk menolak atau menerima hipotesis, pada tingkat kesalahan yang digunakan sebesar $5 \%$ atau 0.05 , pada taraf signifikan $95 \%$ adalah:

a. Jika thitung < $\mathrm{t}$ tabel, maka Ho diterima dan menolak Ha, yang artinya koefisien korelasi berganda yang dihitung tingkat signifikan.

b. Jika thitttng> ttabel maka Ho ditolak dan menerima Ha yang artinya koefisien korelasi berganda yang dihitung tingkat signifikan dan menunjukan terdapat pengaruh secara parsial.

\section{HASIL DAN ANALISIS}

\section{Perhitungan Analisis Jalur}

Dari basil perhitungan di atas, diperoleh informasi bahwa pengaruh gabungan dari faktor-faktor psikologis terhadap keputusan wisatawan dalam mengunjungi Taman Bunga Nusantara di Kabupaten Cianjur adalah sebesar 38,2\%, sedangkan sisanya sebesar 61,8\% merupakan pengaruh dari faktor lain yang tidak diteliti.

Jika digambarkan, nilai korelasi antar variabel bebas, koefisien jalur dan pengaruh variabel lain yang sudah diperoleh tersebut dapat disajikan sebagai berikut: 


\section{Gambar 1}

\section{Diagram Jalur Xi, X2, X3, X4, Ss, X6 dan X7 terhadap Y}

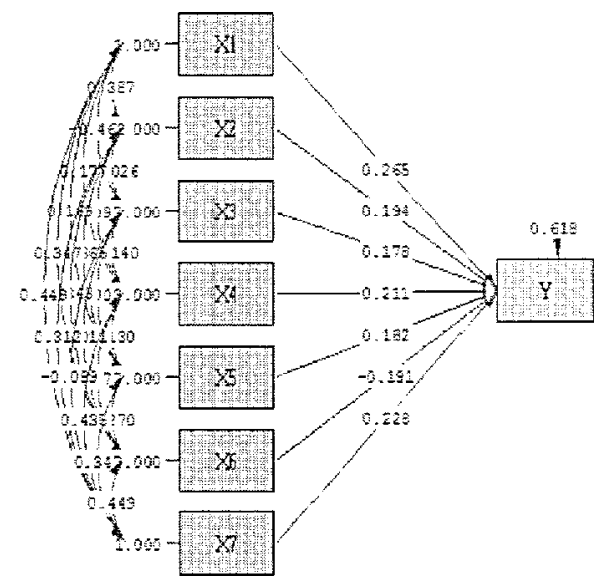

\section{Pengujian Hipotesis}

\section{Pengujian Hipotesis Simultan (Uji F)}

Pengujian hipotesis simultan digunakan untuk membuktikan apakah variabel kualitas kehidupan kerja yang terdiri dari perception (Xi), learning (X2), memory (X3), motives (X4), personality (X5), emotions (X6), attitudes (X7), berpengaruh signifikan terhadap variabel dependen (Y) yaitu keputusan berkunjung.

Uji statistik yang telah dilakukan mengikuti distribusi F-Snodecor dengan a $=5 \%$, derajat kebebasan $\mathrm{dbi}=7$, dan $\mathrm{db} 2=120-7-1=112$, diperoleh $\mathrm{F}$ tabel $=2,092$. Dari hasil perhitungan terlihat bahwa nilai F-hitung yang diperoleh $(9,780)>$ F-tabel $(2,092)$, sesuai dengan kriteria pengujian hipotesis bahwa Ho ditolak. Artinya secara simultan faktor- faktor psikologis berpengaruh signifikan terhadap keputusan wisatawan dalam mengunjungi Taman Bunga Nusantara di Kabupaten Cianjur.

\section{Pengujian Hipotesis Parsial (Uji T)}

Uji Hipotesis Parsial (Xi)

Nilai t-hitung yang diperoleh sub variabel perception (Xi) sebesar 2,593 berada diluar nilai t-tabel $(-1,981$ dan 1,981$)$ sehingga berada di daerah penolakan Ho, dengan demikian dapat disimpulkan bahwa secara parsial, perception (Xi) berpengaruh signifikan terhadap keputusan wisatawan untuk berkunjung (Y) ke Taman Bunga Nusantara di Kabupaten Cianjur.

Uji Hipotesis Parsial (X2)

Nilai t-hitung yang diperoleh sub variabel learning (X2) sebesar 2,217 berada diluar nilai t-tabel $(-1,981$ dan 1,981) sehingga berada di daerah penolakan Ho, dengan demikian dapat disimpulkan bahwa secara parsial, learning (X2) berpengaruh signifikan terhadap keputusan wisatawan untuk berkunjung $(\mathrm{Y})$ ke Taman Bunga Nusantara di Kabupaten Cianjur.

Uji Hipotesis Parsial (X3)

Nilai t-hitung yang diperoleh sub variabel memory (X3) sebesar 2,036 berada diluar nilai t-tabel $(-1,981$ dan 1,981$)$ sehingga berada di daerah penolakan Ho, dengan demikian dapat disimpulkan bahwa 
secara parsial, memory (X3) berpengaruh signifikan terhadap keputusan wisatawan untuk berkunjung (Y) ke Taman Bunga Nusantara di Kabupaten Cianjur.

Uji Hipotesis Parsial (X4)

Nilai t-hitung yang diperolch sub variabel motives (X4) sebesar 2,525 berada diluar nilai t-tabel $(-1,981$ dan 1,981) sehingga berada di daerah penolakan Ho, dengan demikian dapat disimpulkan bahwa secara parsial, motives $(\mathrm{X} 4)$ berpengaruh signifikan terhadap keputusan wisatawan untuk berkunjung $(\mathrm{Y})$ ke Taman Bunga Nusantara di Kabupaten Cianjur.

Uji Hipotesis Parsial (X5)

Nilai t-hitung yang diperoleh sub variabel personality (X5) sebesar 2,183 berada diluar nilai ttabel $(-1,981$ dan 1,981) sehingga berada di daerah penolakan Ho, dengan demikian dapat disimpulkan bahwa secara parsial, personality (X5) berpengaruh signifikan terhadap keputusan wisatawan untuk berkunjung $(\mathrm{Y})$ ke Taman Bunga Nusantara di Kabupaten Cianjur.

Uji Hipotesis Parsial (X6)

Nilai t-hitung yang diperoleh sub variabel emotions (X6) sebesar -2,183 berada diluar nilai t-tabel $(-1,981$ dan 1,981) sehingga berada di daerah penolakan Ho, dengan demikian dapat disimpulkan bahwa secara parsial, emotions (X6) berpengaruh signifikan terhadap keputusan wisatawan untuk berkunjung (Y) ke Taman Bunga Nusantara di Kabupaten Cianjur.

Uji Hipotesis Parsial (X7)

Nilai t-hitung yang diperoleh sub variabel attitudes (X7) sebesar 2,282 berada diluar nilai t-tabel $(-1,981$ dan 1,981) sehingga berada di daerah penolakan Ho, dengan demikian dapat disimpulkan bahwa secara parsial, attitudes (X7) berpengaruh signifikan terhadap keputusan wisatawan untuk berkunjung (Y) ke Taman Bunga Nusantara di Kabupaten Cianjur.

Dari hasil pengkategorian yang telah dilakukan, skor aktual yang diperoleh variabel faktor-faktor psikologis sebesar 4491. Nilai ini berada dalam kelas interval antara 4500 dan 5850 dan berada dalam kategori baik. Hal ini menunjukan para wisatawan yang berkunjung ke Taman Bunaa Nusantara memiliki faktor-faktor psikologis yang baik.

Sedangkan hasil dari pengkategorian yang dilakukan untuk ndikator-indikator keputusan berkunjung didapat bahwa skor aktual yang diperoleh keputusan berkunjung sebesar 4491. Nilai ini berada dalam kelas interval antara 3150 dan 4500 dan berada dalam kategori rendah. Hal ini menunjukan para wisatawan kurang berminat untuk berkunjung ke Taman Bunga Nusantara.

\section{SIMPULAN}

Kondisi aktual faktor-faktor psikologis wisatawan tergolong baik ketika berkunjung ke Taman Bunga Nusantara, yang terdiri dari tujuh sub variabel, yaitu perception, learning, memory, motives, personality, emotions, dan attitudes.

Wisatawan menilai keputusan untuk berkunjung ke Taman Bunga Nusantara dalam kategori rendah. Penilaian keputusan berkunjung ini terdiri dari lima dimensi yaitu problem recognition, information search, alternative evaluation and selection, Outlet selection and purchase, serta pot-purchase process.

Secara simultan, faktor-faktor psikologis yang berpengaruh signifikan terhadap keputusan wisatawan dalam mengunjungi Taman Bunga Nusantara di Kabupaten Cianjur dengan kontribusi pengaruh yang diberikan sebesar 38,2\%, sedangkan sisanya sebesar $61,8 \%$ merupakan pengaruh dari variabel lain yaitu eksternal faktor yang terdiri dari culture, subculture, demographics, social status, family, dan marketing strategy. 


\section{DAFTAR REFERENSI}

Arikunto, Suharsimin, 1998, Prosedur Penelitian, Jakarta: PT. Rineka Cipta,

Cooney, Kenneth A., Roger J. Best, Del I. Hawkins, 2001, Consumer Behavior Buliding

Marketing Strategy 8th edition, New York : Mc Graw Hills

Ghazali, Imam. 2001. Aplikasi Analisis Multi variative Dengan Program SPSS, Semarang : Badan Penerbit UNDIP

Nirwana, SK Sitepu, 1994, Analisis Jahn. Path, Bandung

Singarimbuan, Masri dan Sofian Effendi, 1989. Metode Penelitian Survei, Jakarta: LP3ES.

Sutisna, 2006, Perilaku Konsumen \& Komunikasi Pemasaran, Bandung : Rosdakarya, Rineka Cipta.

Sugiyono, 2005, Statistika Untuk Penelitian, Jakarta: Alfabeta.

Sumarwan, Ujang, 2004, Perilaku Konsumen : Teori dan Penerapannya dalam Pemasaran, Bogor : Ghalia Indonesia. 